\title{
OPTIMALISASI PERTUMBUHAN TANAMAN KELAPA SAWIT DI TANAH SPODOSOL
}

\section{Muhdan Syarovy*, Eko Noviandi Ginting, Dimas Wiratmoko dan Heri Santoso}

Pusat Penelitian Kelapa Sawit (PPKS), Medan 20158

*Corresponding author: muhdan.syarovy@ gmail.com

\begin{abstract}
ABSTRAK
Semakin terbatasnya lahan yang optimal, membuat pengembangan kelapa sawit saat ini diarahkan ke lahan marginal. Lahan dengan jenis tanah spodosol merupakan salah satu lahan marginal yang telah dimanfaatkan untuk pengembangan kelapa sawit. Selain memiliki lapisan spodik, faktor pembatas lain dari tanah spodosol ialah memiliki tekstur kasar (terbentuk dari bahan pasir atau pasir berlempung) dengan iklim dingin dan tropika basah serta bersifat masam. Akibatnya, tanah tersebut memiliki kemampuan yang rendah dalam menahan air dan pencucian hara akan menjadi lebih tinggi. Pengolahan yang tepat sangat diperlukan agar kelapa sawit yang ditanam pada tanah spodosol dapat tumbuh dengan optimal. Beberapa cara yang dapat dilakukan adalah dengan mengidentifikasi tanah spodosol dan tingkat kedalaman lapisan spodik, memperbaiki media pertumbuhan tanaman, memperbaiki iklim mikro dan pemupukan yang tepat.
\end{abstract}

Kata kunci: Lahan marginal, kelapa sawit, spodosol

\section{PENDAHULUAN}

Kelapa sawit merupakan salah satu komoditas perkebunan terbesar di Indonesia. Komoditas ini telah tumbuh dengan pesat dan menyumbang pendapatan asli daerah maupun devisa negara yang cukup tinggi pada sektor non migas. Berdasarkan data Dijenbun (2014), total luas perkebunan kelapa sawit pada tahun 2014 mencapai 10,9 juta ha dan diperkirakan pada tahun 2015 luas perkebunan tersebut akan terus bertambah menjadi 11,4 juta ha. Tentunya, semakin pesatnya perkembangan tersebut mengakibatkan lahan-lahan yang memiliki tingkat kesuburan tinggi menjadi semakin terbatas. Hal ini memaksa para pekebun untuk memanfaatkan lahan-lahan marjinal yang memiliki beberapa faktor pembatas untuk pengusahaan perkebunan kelapa sawit. Salah satu lahan marginal yang sudah dimanfaatkan untuk perkebunan kelapa sawit saat ini adalah tanah spodosol.
Tanah spodosol merupakan tanah yang terbentuk dari bahan induk pasir kuarsa, memiliki ciri adanya lapisan pasir masam berwarna putih abu-abu (horison albik) dan lapisan berupa akumulasi besi, alumunium dan/atau bahan organik(lapisan spodik) (Hardjowigono, 1993).Tanah spodosol memiliki luas sekitar 2,16 juta ha atau $1,1 \%$ di seluruh wilayah Indonesia (Subagyo et al., 2004).Tanah jenis ini umumnya dijumpai di daerah tropika basah seperti Sumatera, Kalimantan, Sulawesi, dan Papua (Suharta dan Yatno, 2009).

Tanah spodosol merupakan tanah yang miskin hara (Wiratmokoet al. 2007; Suharta dan Yatno, 2009). Hal ini dapat dilihat dari karakteristik kandungan karbon (C) yang agak rendah $(0,11-1,31 \%)$ dan agak tinggi $(4,62 \%)$ pada horizon spodik. Memiliki kandungan Nitrogen $(\mathrm{N})$ rendah hingga agak rendah $(0,10-0,11 \%)$, rasio $\mathrm{C} / \mathrm{N}$ agak rendah $(0,10-0,11 \%)$ pada lapisan atas dan tinggi pada lapisan spodik (46,2\%). Memiliki fosfor (P) tersedia rendah (1-8 ppm) pada seluruh lapisan, 
kapasitas tukar kation (KTK) tergolong rendah hingga sedang pada seluruh horizon $(7,64-14,98)$, kejenuhan basa (KB) rendah (1-3\%) pada seluruh lapisan, memiliki $\mathrm{pH}$ yang masam $(\mathrm{pH} 3,7-4,5)$ (Adiwiganda et al.1993).

Tanah spodosol memiliki dua faktor pembatas berat yang perlu menjadi perhatian yaitu kedalaman lapisan spodik dan tekstur tanah berpasir. Kedalaman lapisan spodik berkaitan dengan kemudahan akar dalam menembus tanah, sedangkantekstur tanah berpasir akan mengakibatkan rendahnya kemampuan tanah dalam menahan air dan peluang tercucinya hara juga semakin besar. Faktor pembatas lain yang berpotensi dapat menghambat pertumbuhan tanaman ialah drainase buruk dan kemasaman tanah (Wiratmokoet al. 2007; Kasno dan Subarja, 2010).

Tanah spodosol memiliki potensi yang tergolong rendah dan jarang digunakan untuk usaha pertanian. Menurut Koedadiri et al.(1995), tanaman kelapa sawit yang ditanam di lahan spodosol pada umur 9 tahun memiliki produktivitas yang rendah yaitu hanya berkisar 5,4 ton TBS/ha/tahun. Namun demikian, banyak pekebun yang tetap memaksakan untuk menanam kelapa sawit pada tanah jenis ini. Untuk itu, diperlukan tindakan kultur teknis yang tepat, agar tanaman kelapa sawit yang di tanam pada lahan spodosol dapat tumbuh dan berproduksi dengan optimal.

\section{TEKNOLOGI PENGELOLAAN TANAH SPODOSOL}

Adanya lapisan spodik dan tekstur tanah yang kasar (berpasir) merupakan faktor pembatas utama yang memerlukan penanganan khusus. Pengembangan paket teknologi yangdifokuskan pada dua faktor pembatas tersebut diharapkan dapat meningkatkan pertumbuhan dan produktivitas tanaman kelapa sawit di lahan spodosol. Beberapa teknologi tersebut antara lain identifikasi kedalaman spodik dan tingkat kekerasan lapisan spodik, memperbaiki media tumbuh tanaman, memperbaiki iklim mikro dan teknologi pemupukan yang tepat.

\section{a. Identifikasi kedalaman dan tingkat kekerasan lapisan spodik}

Kegiatan identifikasi kedalaman dan tingkat kekerasan lapisan spodik merupakan kegiatan yang sangat penting dilakukan. Kedalaman lapisan spodik merupakan faktor utama yang harus diperhatikan. Lapisan spodik memiliki tekstur yang keras yang mengakibatkan sulitnya akar dan air dalam menembusnya. Menurut Kasno dan Subarja (2010), kedalam lapisan spodik pada tanah spodosol berkisar antara 30-70 cm dibawah permukaan tanah. Namun demikian, kelapa sawit membutuhkan solum tanah $\geq 80 \mathrm{~cm}$ tanpa lapisan batuan didalamnyaagar dapat tumbuh dan berkembang dengan optimal (Lubis, 2008). Untuk dapat tumbuh dengan baik di tanah spodosol, setidaknya kedalaman lapisan spodik dikehendaki kelapa sawit ialah lebih dari $75 \mathrm{~cm}$ (Wiratmoko, et al. 2015).

\section{b. Memperbaiki media tumbuh tanaman}

Tanah spodosol memiliki sifat fisik tekstur yang kasar sehingga perbaikan media pertumbuhan tanaman sangat penting untuk dilakukan. Bahan amelioran diharapkan dapat memperbaiki sifat fisik, kimia dan biologi tanah (Lestari, 2009). Pemberian berbagai bahan amelioran organik seperti aplikasi tandan kosong kelapa sawit (TKS) sangatbermanfaat untuk meningkatkan kelembaban, mengurangi evaporasi permukaan tanah, memperbaiki sifat fisik tanah dan memperkaya bahan organik (Darmosarkoro et al. 2001). Hasil penelitian Santoso, et al. (2013) pemberian TKS sebanyak $200 \mathrm{~kg} /$ pohon atau kompos TKS sebanyak $100 \mathrm{~kg} /$ pohon yang dipadukan dengan penerapan Best Management Practices memberikan tren peningkatan produktivitas tanaman di 
tanah spodosol.Lebih banyak lagi Santoso, et al. (2015)menyatakan bahwa penggunaan bahan amelioran kompos TKS di pembibitan kelapa sawitmenunjukaan pemberian kompos TKS dapat meningkatkan tinggi tanaman, diameter batang, jumlah daun, berat kering total, dan serapan hara $\mathrm{N}, \mathrm{P}, \mathrm{K}, \mathrm{Ca}$, dan $\mathrm{Mg}$ yang masing-masing sebesar $4,9 \% ; 8,7 \%$; $5,7 \%, \quad 12,2 \% ; 18,8 ; 24,0 \% ; 17,04 \%$; $15,8 \%$; dan $13,6 \%$ dibandingkan dengan kontrol.

Selain penggunaan bahan organik, bahan amelioran lainnya seperti fly ash juga telah digunakan untuk meningkatkan pertumbuhan tanaman kelapa sawit pada tanah berpasir. Fly ash merupakan limbah

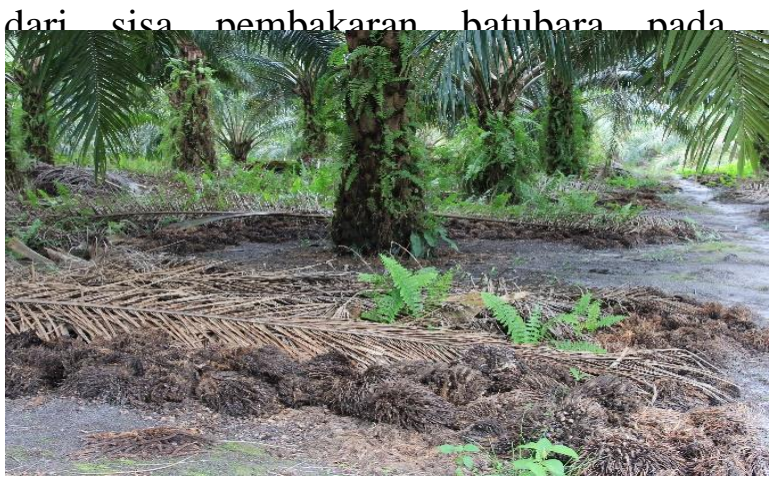

(a) pembangkit listrik (Wardani, 2008). Fly ash dapat digunakan sebagai bahan amelioran karena dapat meningkatkan retensi air pada tanah berpasir (Gangloff $e t$ al. 1999) danmeningkatkan $\mathrm{pH}$ tanah (Kovacik et al. 2011; Natalia et al. 2012; Tarkalson et al., 2010).Hasil penelitian Santoso et al. (2015) menunjukkan bahwa pemberian fly ash dengan dosis 10-20 ton/ha memberikan pengaruh terhadap tinggi tanaman, diameter batang, jumlah daun, berat kering total, dan serapan hara $\mathrm{N}, \mathrm{P}, \mathrm{K}, \mathrm{Ca}$, dan $\mathrm{Mg}$ sebesar 3-24\% dibandingkan dengan tanpa pemberian $f l y$ ash pada tanaman kelapa sawit di main nursery.

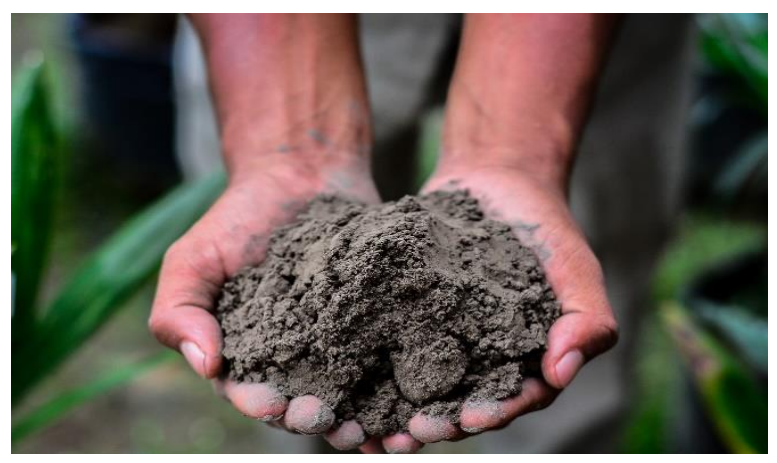

(b)

Gambar 1. Aplikasi bahan amelioran pada kelapa sawit (a) Penggunaan TKS pada tanaman kelapa sawit menghasilkan; (b) fly ash dapat digunakan sebagai bahan amelioran.

Struktur tanah yang porous pada tanah spodosol menyebabkan air akan terlalu cepat hilang sehingga kesempatan tanaman untuk memanfaatkan air tersebut relatif kecil. Selain itu, terdapatnya lapisan spodik yang sulit ditembus oleh air maupun akar akan menyebabkan air cepat mengalir ke daerah lereng dibawahnya (Tala'ohu et al., 2008). Selain pemberian bahan organik yang dapat meningkatkan kapasitas tanah dalam meretensi air, penerapan bangunan konservasi tanah dan air juga dapat membantu dalam penyediaan air. Pembuatan slit pit (rorak) dan parit discontinue sangat berguna untuk mengatasi kelebihan air pada musim hujan dan menyediakan air pada saat musim kemarau. Siregar et al. (1996) menambahkan,selain berfungsi sebagi penyangga pencucian pupuk, rorak juga berfungsi sebagai penampung cadangan air dan menjaga kelembaban pertanaman pada musim kemarau. Rorak dibangun dengan panjang $8 \mathrm{~m}$, lebar $0,4 \mathrm{~m}$, dan dalam 0,6 m. Satu rorak digunakan untuk 3 tanaman dimana setiap rorak dibangun parit overflow yang digunakan sebagai penghubung antar rorak dengan lebar 20 $\mathrm{cm}$ dan dalam $30 \mathrm{~cm}$ (Santoso, et al. 2013). Aplikasi rorak pada pertanaman kelapa sawit dapat meningkatkan produksi tandan buah segar sebesar 23,6 ton/ha jika dibandingkan dengan tanpa aplikasi rorak 20,8 ton per ha (Murtilaksono et al.2008). 


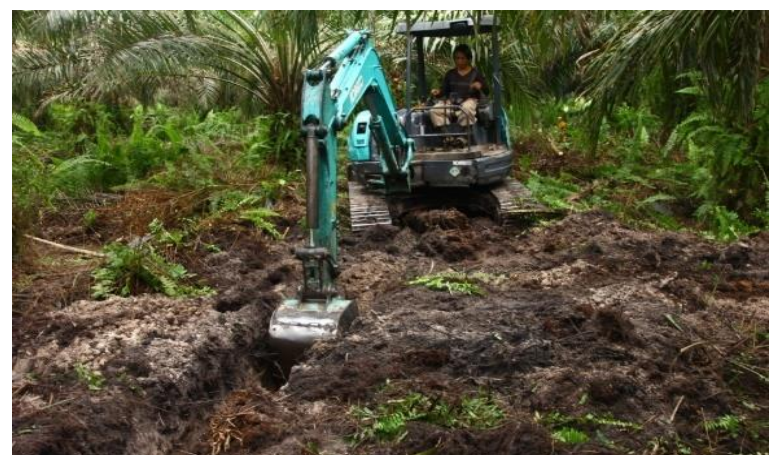

(a)

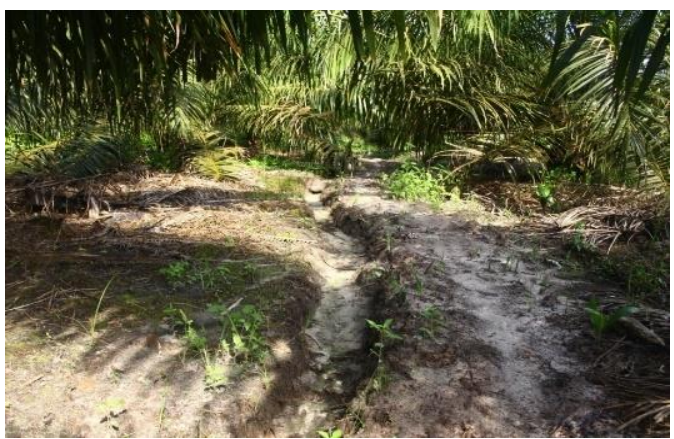

(b)

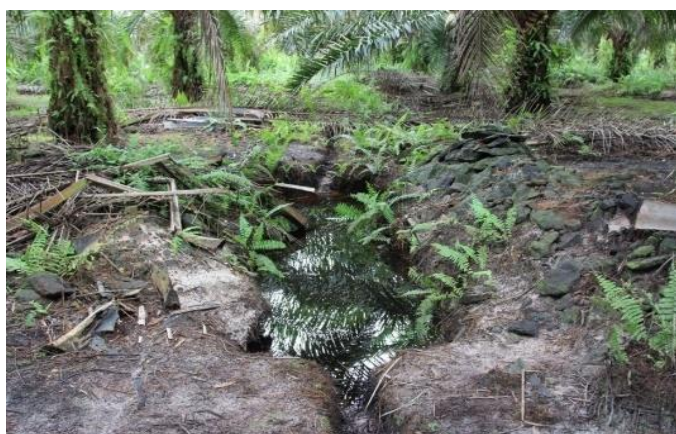

(c)

Gambar 2. Bangunan konservasi tanah dan air; (a) proses pembuatan rorak menggunakan escavator; (b) over flow merupakan penghubung antar rorak; dan (c) rorak yang terisi dengan air.

\section{c. Memperbaiki Iklim Mikro}

Penanaman tanaman penutup tanah sepertilegume cover crop (LCC), penanaman tanaman pakis lunak, dan pengaturan peletakkan pelepah merupakan cara sederhana yang sering dilakukan oleh pekebun dalam usaha perbaikan iklim mikro ini. Perbaikan ikim mikroberfungsi untuk menjaga kelembaban, mengurangi penguapan (Santoso, et al.2013) dan juga merupakan salah satu upaya yang dapat dilakukan untuk mengatasi kekeringan (Siregar et al. 1996). Penanaman LCC khususnya pada masa tanaman belum menghasilakan (TBM) dapat menekan pertumbuhan gulma, mengurangi pencucian hara, dan memperbaiki sifat kimia tanah dengan cara menambat $\mathrm{N}$ dari bintil akarnya (Darlan et al. 2011). Haron et al. (2000) menambahkan, biomasa yang dihasilkan LCC ialah sebesar $5.370 \mathrm{~kg} / \mathrm{ha}$ dengan sumbangan hara mencapai mencapai 113,3 kg N; 11,28 kg P; 105,8 $\mathrm{kg} \quad \mathrm{K} ; 27,92 \mathrm{~kg} \quad \mathrm{Ca} ;$ dan $9,13 \mathrm{~kg}$
Mg.Sementara itu, penanaman tanaman pakuan seperti Nephrolepissebagai penutup tanah dapat meningkatkan kesuburan tanah sebesar 12,74\%, N sebesar $15 \%$, P sebesar 26,82\%, dan $\mathrm{K}$ sebesar $17,45 \%$ dibandingkan dengan tanah yang tidak ditanami Nephrolepis (Arianti et al. 2015).

Manajemen pengendalian gulma yang dilakukan secara selektif dan efisien (selectif weed control) atau menghindari sistem pengendalian blanked (full weeding) merupakan tindakan yang dapat dilakukan dalam memperbaiki iklim mikro. Pengendalian gulma sebaiknya difokuskan tehadap gulma anakan kayu dan tukulan, sedangkan gulma lainnya seperti rumput lunak dan pakisan cukup dikendalikan secara selektif atau bahkan dipelihara. Darmosarkoro et al. (2001) menjelaskan pengendalian gulma sebaiknya dilakukan tidak disemprot, melainkan menggunakan babat layang 
yang dipotong dengan ketinggian $\pm 30 \mathrm{~cm}$ dari permukaan tanah.

Pengaturan peletakkan pelepah biasanya dilakukan dengan cara menebar pelepah-pelepah daun setelah pruning atau panen. Pelepah ini disusun merata digawangan mati pada tanaman kelapa sawit. Pelapah ini berfungsi sebagai mulsa yang menjaga kelembaban dan suhu di dalam tanah serta mengurangi kehilangan air akibat penguapan pada musim kemarau Darmosarkoro et al. (2001). Selain pelepah, aplikasi tandan kosong juga dapat dilakukan sebagai mulsa (Siregar et al., 1996).

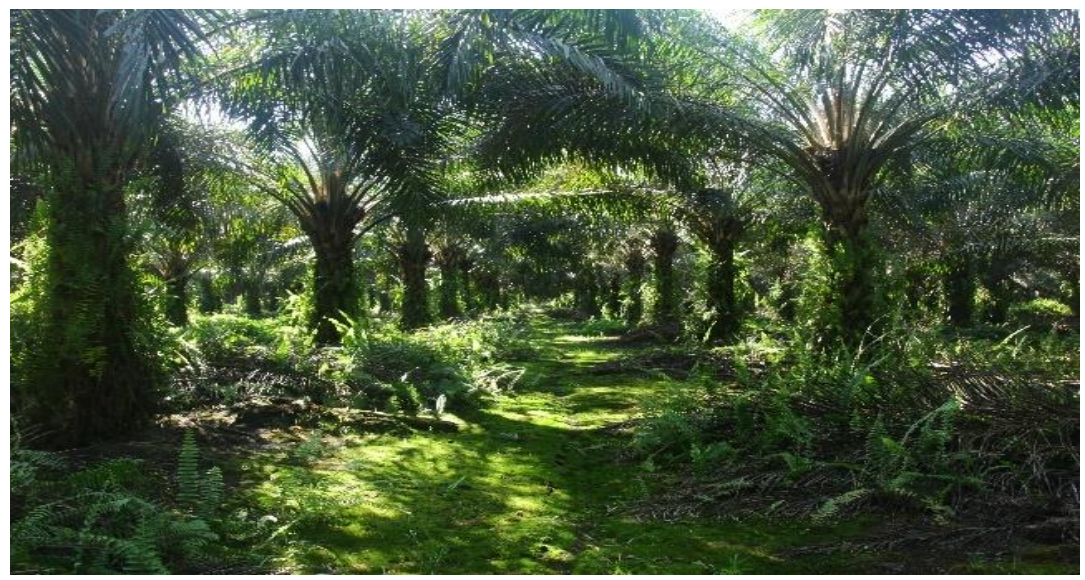

a

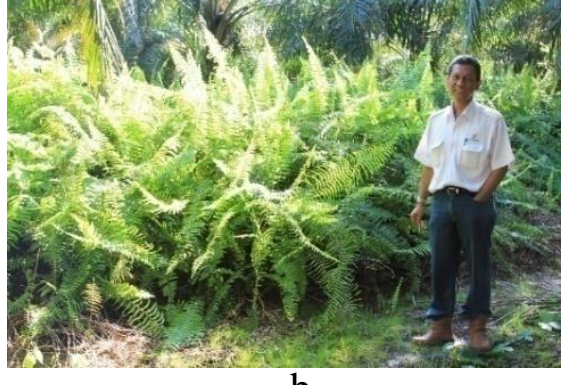

b

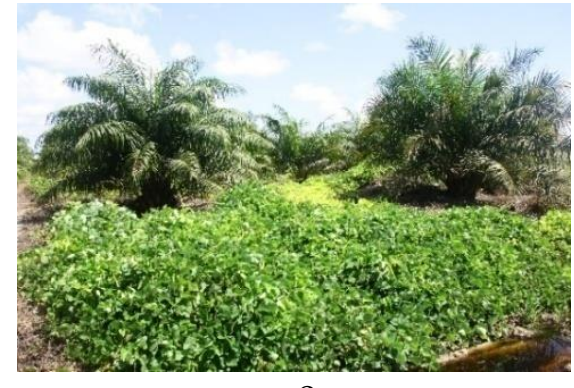

C

Gambar 3. Perbaikan iklim mikro, melalui: (a) pengaturan peletakkan pelepah; (b) penanaman tanaman pakisan sebagai penambah bahan organik; (c) Penamanaman LCC Mucuna Bracteata pada saat TBM.

\section{d. Teknologi pemupukan yang tepat}

Pada prisnsipnya pemupukan harus mengikuti kaidah 4T yaitu tepat dosis, jenis, waktu, dan cara. Pada tanah spodosol, penggunaan pupuk slow releasesangat dianjurkan pada tanaman kelapa sawit karena teksturnya yang berpasir (Kasno dan Subardja, 2008).Penggunaan pupuk slow release merupakan salah satu cara yang digunakan untuk meminimalkan hilangnya pupuk karena tercuci pada tanah berpasir terutama hara $\mathrm{N}$ dan $\mathrm{K}$ (memiliki tingkat kelarutan yang tinggi terhadap air).Penggunaan pupuk $\mathrm{N}$ secara slow release sangat disarankan untuk tanah berpasir karena dapat mengefisienkan penggunaan pupuk N. Jika dibandingkan dengan penggunaan dari sumber nitrogen lainnya, penggunaan pupuk nitrogen slow release dapat meningkatkan produktifitas dari gandum di tanah berpasir (Zeidan dan Kramany, 2001). Hasil penelitian lainnya dilakukan oleh Winarna et al. (2003) 
dimana penggunaan pupuk lambat tersedia dengan kandungan 10-10-16-4 + mikro dengan dosis 12 tablet/bibit dan frekuensi 3 kali selama di main nursery memberikan efektivitas agronomis nisbi yang sama bahkan lebih dibandingkan perlakuan pemupukan standar.

\section{PRODUKTIVITAS KELAPA SAWIT SPODOSOL \\ TANAMAN DI TANAH}

Penerapan teknologi pengelolaan tanah spodosol yang tepat serta diikuti dengan aplikasi BMP (Best Management

Tabel 1. Produktivitas tanaman kelapa sawit tahun tanam 2004 di lahan Spodosol Kalimantan Tengah

\begin{tabular}{cccc}
\hline Tahun & $\begin{array}{c}\text { Produktivitas } \\
\text { (ton/ha) }\end{array}$ & $\begin{array}{c}\text { Jumlah } \\
\text { Tandan }\end{array}$ & $\begin{array}{c}\text { Rerata } \\
\text { BeratTandan }(\mathrm{kg})\end{array}$ \\
\hline 2009 & $10,5 \pm 4,75$ & $19,6 \pm 5,02$ & $4,5 \pm 0,55$ \\
2010 & $11,2 \pm 5,05$ & $16,0 \pm 4,72$ & $5,8 \pm 1,08$ \\
2011 & $16,0 \pm 4,68$ & $14,0 \pm 2,33$ & $8,5 \pm 1,58$ \\
2012 & $26,5 \pm 4,23$ & $19,6 \pm 3,36$ & $10,5 \pm 1,40$ \\
\hline
\end{tabular}

Sumber :Santosoet al. (2013)
Practice) lainnya pada tahun 2009 hingga 2012, menunjukkan peningkatan produksi hingga 26,5 ton TBS/ha (Tabel 1). Jika dikaitkan dengan potensi produktivitas tanaman kelapa sawit pada kelas kesesuaian lahan S3 (Tabel 2), hanya pada tahun ke-8 (2012) yang produktivitasnya telah tercapai. Hal ini menunjukkan bahwa penerapan teknologi pengelolaan tanah spodosol yang diutamakan pada penyediaan unsur hara yang cukup, telah berhasil memenuhi kebutuhan tanaman sehingga tanaman berproduksi secara optimal.

Tabel 2. Potensi produktivitas tanaman kelapa sawit umur 5-8 tahun pada berbagai kelas kesesuaian lahan.

\begin{tabular}{|c|c|c|c|c|c|c|c|c|c|}
\hline \multirow[t]{2}{*}{ Umur/Kelas } & \multicolumn{3}{|c|}{$\begin{array}{l}\text { Produktivitas } \\
\text { (ton/ha) }\end{array}$} & \multicolumn{3}{|c|}{$\begin{array}{l}\text { RerataJumlahTandan } \\
\text { (tandan/pohon) }\end{array}$} & \multicolumn{3}{|c|}{$\begin{array}{l}\text { Rerataberattandan } \\
\qquad(\mathrm{kg} / \text { tandan })\end{array}$} \\
\hline & $\mathrm{S} 1$ & $\mathrm{~S} 2$ & S3 & $\mathrm{S} 1$ & $\mathrm{~S} 2$ & S3 & $\mathrm{S} 1$ & $\mathrm{~S} 2$ & S3 \\
\hline 5 Tahun & 19 & 17 & 15 & 18,5 & 17,2 & 16 & 7,8 & 7,5 & 7,1 \\
\hline 6 Tahun & 23 & 21 & 19 & 17,1 & 16,1 & 15,5 & 10,2 & 9,9 & 9,3 \\
\hline 7 Tahun & 28 & 26 & 23 & 16,1 & 15,4 & 15,1 & 13,2 & 12,8 & 11,5 \\
\hline 8 Tahun & 32 & 28 & 26 & 15,3 & 14,8 & 14,3 & 15,8 & 14,3 & 13,8 \\
\hline
\end{tabular}

\section{SIMPULAN}

Lahan spodosol merupakan lahan marginal yang mempunyai dua faktor pembatas utama untuk pertanaman kelapa sawit yaitu adanya lapisan spodik dan tekstur berpasir. Penerapan teknologi pengelolaan tanah spodosol yang tepat sangat dianjurkan agar tanaman kelapa sawit dapat tumbuh dan berproduksi secara optimal. Beberapa teknologi pengelolaan tersebut antara lain ialah dengan mengidentifikasi kedalaman dan tingkat kekerasan lapisan spodik; membaiki media tumbuh tanaman yang berfungsi untuk memperbaiki sifat fisik, kimia, dan biologi tanah serta penyediaan air pada saat musim kemarau; memperbaiki iklim mikro sebagai penjaga kelembaban dan mengurangi evaporasi; dan teknologi pemupukan yang tepat untuk menghindari mudahnya pupuk tercuci. Peningkatan produktivitas tanaman didapatkan pada tahun ke-4 setelah aplikasi paket teknologi pengelolaan tanah spodosol yaitu sebesar 26 ton TBS/ha/thn di Kalimantan Tengah.Dengan penerapan teknologi yang 
tepat, tanah spodosol dapat dimanfaatkan untuk perkebunan kelapa sawit.

\section{DAFTAR PUSTAKA}

Adiwiganda, R., A. D. Koedadiri, dan Z. Pulungan. 1993. Karakterisasi Tanah Spodosol pada Formasi Geologi Minas (Qpmi). Buletin PPKS 1993. Vol. 1 (2) : 163-173.

Arianti, M., S. Yahya, K. Murtilaksono, Suwarto, dan H. H. Siregar. 2015. International Journal of Science: basic Aplication and Aplied Research. Vol. 19 (1) : 325-333.

Darlan N.H., Suroso R., Heri S. 2011. Cover crop management untuk mendukung pemupukan yang optimum di perkebunan kelapa sawit. Prosiding Pertemuan Teknis Kelapa Sawit 2011, Batam 4 - 6 Oktober 2011.

Darmosarkoro, W., I. Y. Harahap. Dan E. Syamsuddin. 2001. Pengaruh Kekeringan pada Tanaman Kelapa Sawit dan Upaya Penanggulangannya. Warta PPKS. Vol. 9 (3): 83-96.

Ditjenbun. 2014. Statistik Perkebunan Indonesia 2013-2015.

KelapaSawit. DirektoratJenderal Perkebunan.

KementerianPertanian. Jakarta.

Gangloff W. J., M. Ghodrati, J. T. Sims, and B. L. Vasilas. 1999. Impact of fly ash amendment and incorporation method on hydraulic properties of a sandy soil. Water, Air, and Soil Pollution 119: 231245.

Hardjowigeno, S. 1993. Klasifikasi Tanah dan Pedogensesis Edisi Pertama. Penerbit Akademika Pressindo. Jakarta.

Haron K., Z.Z. Zakaria, and J.M. Anderson. 2000. Nutrient cycling in an oil palm plantation : The effect of residue management practices during replanting on dry matter and nutrient uptake of young palms. Journal of Oil Palm Research 12 (2) : 29-37.

Kovacik, P. M. Macak, L. Ducsay, M. Halcinova, dan M. Jancich. 2011. Effect of Ash-Fly Mixture Aplication On Soil Fertility. J. Elem. Hal: 215-225.

Kasno A., dam Subardja. 2010. Soil Fertility and Nutrient Management on Spodosol for Oil Palm. Agrivita. Vol. 32 (3).

Koedadiri, A.D., R. Adiwiganda, dan Z. Poeloengan. 1995. Keragaan Tanaman Kelapa Sawit (Elaeis guinensis Jacq) pada Tanah Typic Paleudults, Psamentic Paleudults, dan Haplorthods. Prosiding Seminar Nasional HITI. Kongres HITI VII, Serpong, Bogor.

Lestari, A. P. 2009. Pengembangan Pertanian Berkelanjutan Melalui Substitusi Pupuk Anorganik dengan Pupuk Organik. Jurnal Agronomi 13 (1).

Lubis, A. 2008. Kelapa Sawit (Elaeis guinensis Jacq) di Indonesia. Pusat Penelitian Kelapa Sawit. Medan.

Natalia, R. Hayati dan Juanidi, 2012. Pengaruh Pemberian Abu Terbang (Fly ash) terhadap Akumulasi Arsen (As) dan Produksi Beberapa Jenis Tanaman Sawi di Tanah Gambut.

http://jurnal.untan.ac.id/index.php/j spp/article/view/243 diakses pada 2 Januari 2014.

Murtilaksono, K., W. Darmosarkoro, E. S. Sutarta, H. H. Siregar. 2008. Upaya Peningkatan Produksi Kelapa Sawit melalui Penerapan Teknik Konservasi Tanah dan Air. Jurnal Tanah Tropika. Vol. 14 (2) : 135142.

Santoso, H. S., E. S. Sutarta, W. Darmosarkoro. 2013. Pengelolaan Tanah dam Penggunaan Pupuk NPK Palmo pada Tanah Spodosols di PT Bumitama Gunajaya Agro. Pusat Penelitian Kelapa Sawit. Medan. 
Santoso, H. S., M. Syarovy, I. Pradiko, Winarna. 2015. Penggunaan Fly Ash sebagai Alternatif Bahan Amelioran pada Tanah Berpasir (Spodosol) di Perkebunan Kelapa Sawit. Prosiding PTKS 2015. Yogyakarta.

Siregar, H. H., A. Purba, Z. Poeloengan. 1996. Kajian Modifikasi Iklim Mikro dan Masalah Kekeringan pada Pertanaman Kelapa Sawit. Warta PPKS. Vol 4. No. 3 : 137142.

Suharta, N dan E. Yatno, 2009. Karakteristik Spodosols, Kendala dan Potensi Penggunaannya. Jurnal Sumberdaya Lahan. Vol.3 (1) : 114.

Subagyo, H., N. Suharta, dan A. B. Siswanto. 2004. Tanah-tanah pertanian di Indonesia. Hlm 21-66. Dalam A.Adimihardja et al (Eds). Sumberdaya Lahan Indonesia dan Pengelolaannya.

Puslitbangtanak.Cetakan kedua.

Tarkalson, D., C.A. Shapiro dan J.L. Petersen. 2010. Use of Fly ash as a Liming Material of Corn and Soybean Production on an Acidic Sandy Soil. Plant Management Network.

Tala'ohu, S. H., D. Subardja, dan Alkasuma. 2008. Kondisi Biopisik dan Arahan Teknologi Konservasi Tanah pada Perkebunan Kelapa Sawit di Daerah Sungai Landak, Kabupaten Landak, Kalimantan Barat. diakses dari http://balittanah.litbang.pertanian.g o.id/ind/dokumentasi/prosiding200 8pdf/sidik.pdf pada tanggal 1 Juni 2015.

Wiratmoko, D., Winarna, E. Listia, dan M.L. Fadli. 2007. Mengenal Tanah Spodosol dan Kesesuaiannya untuk Tanah Kelapa Sawit. Warta PPKS. Vol. 15 (1): 19-24.

Wiratmoko, N. H. Darlan, Winarna, dan A. R. Purba. 2015. Teknologi Pengelolaan Lahan Sub Optimal untuk Optimalisasi Produksi Kelapa Sawit. Diampaikan pada Seminar Optimalisasi Pemanfaatan Lahan Marginal untuk Usaha Perkebunan. Surabaya.

Wardani, S. P. R. 2008. Pemanfaatan Limbah Batubara (Fly ash) untuk Stabilisasi Tanah Maupun Keperluan Teknik Sipil Lainnya Dalam Mengurangi Pencemaran Lingkungan. http://eprints.undip.ac.id/7029/ diakse pada 2 Januari 2014.

Winarna, E. S. Sutarta, W. Darmosarkoro. 2003. Efektivitas Aplikasi Pupuk Majemuk Lambat Tersedia pada Pembibitan Kelapa Sawit. Jurnal Pusat Penelitian Kelapa Sawit. Vol 11. No. 3: 107-105.

Zeidan, M. S. dan M. F. E. Kramany. 2001. Effect Of Organic Manure and Slow-Release NFertilizers on The Productivity of Wheat (Triticum Aestivum L.) in Sandy Soil. Acta Agronomi Hungaria. Vol 49 No. 4 http://dx.doi.org/10.1556/AAgr.49. 2001.4.9 
